DIVISION OF THE HUMANITIES AND SOCIAL SCIENCES

CALIFORNIA INSTITUTE OF TECHNOLOGY

PASADENA, CALIFORNIA 91125

COLLISION IN PRIVATE VALUE ASCENDING PRICE AUCTIONS

Katerina Sherstyuk

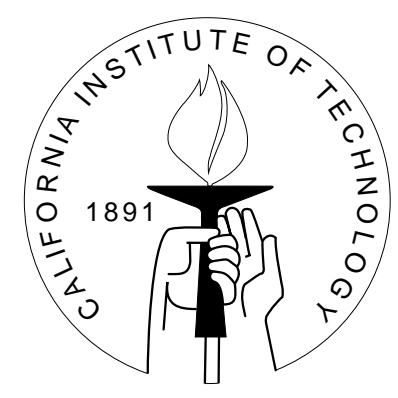

SOCIAL SCIENCE WORKING PAPER 1063 


\title{
Collusion in private value ascending price auctions
}

\author{
Katerina Sherstyuk* \\ University of Melbourne ${ }^{\dagger}$
}

\begin{abstract}
We investigate bidder collusion in one-sided ascending price auctions without communication. If bidding rules in an English-type auction allow bidders to match each others' bids, collusion can be sustained as a Nash equilibrium of a one-shot auction game. Our earlier experiments show that in common value auctions with complete information, collusion does occur and is sustainable even when bidders cannot explicitly coordinate their strategies. In this study, we investigate the robustness of bidders' collusive behavior in private values, private information environments. We find that collusion still occurs as long as the bidders' gains from collusion are high.
\end{abstract}

JEL classification code: C92, D44

Key words: auction experiments; tacit collusion

\footnotetext{
*I would like to thank Dan Levin, Charles Plott, Roger Wilkins and the participants of the March 1999 International Symposium on New Development in Experimental Economics (Osaka, Japan) for helpful discussion and suggestions. Financial support by the Australian Research Council is gratefully acknowledged. All errors are my own.

${ }^{\dagger}$ Department of Economics, University of Melbourne, Parkville, Victoria 3052, Australia. Fax: (61-3)9344-6899; phone (61-3)-9344-5316; email: katya@cupid.ecom.unimelb.edu.au
} 


\section{Introduction}

The issue of bidder collusion in auctions has been gaining increasing interest due to the growing use of auction mechanisms in government procurement and privatization programs in many countries. Bidder collusion, if occurs, may be detrimental for both social efficiency and governments' auction revenue. It is therefore essential to investigate the institutional features that safeguard against collusion and provide for socially efficient outcomes.

Collusion in auction markets has been studied by both economic theorists (Milgrom, 1987; Graham and Marshall, 1987; McAfee and McMillan, 1992) and experimentalists (Isaac and Plott, 1981; Isaac, Ramey and Williams, 1984; Isaac and Walker, 1985; Clauser and Plott, 1993; Artale, 1997; Kwasnica, 1998). Experimental evidence indicates that while double oral auctions are not susceptible to collusion (Isaac and Plott, 1981; Clauser and Plott, 1993), conspiracies can be quite effective in posted-offer and sealed bid markets, provided that the sellers (buyers) are allowed to communicate between periods (Isaac, Ramey and Williams, 1984; Isaac and Walker, 1985; Saijo, Une and Yamaguchi, 1996; Artale, 1997; Kwasnica, 1998).

We study bidder collusion in one-sided ascending price oral auctions where no explicit communication among bidders is allowed. Many researchers argue that ascending English-type auctions have an advantage over the sealed bid procedures in solving complex allocation problems such as allocation of airwave licenses (McAfee and McMillan, 1996). The advantage is due to a richer action space and a superior information feedback that

bidders get in iterative procedures as compared to one-shot sealed-bid auctions. However, it is also well recognized that these very features of iterative procedures make such auctions more susceptible to bidder collusion (Milgrom, 1987, 1998; Crampton, 1998). Fine details of institutional design may make a difference in safeguarding against or in facilitating bidder collusion.

We study the importance of the strict bid improvement rule (also called the increment rule) in providing for competitive outcomes in one-sided ascending price auctions. If bidding rules in an English-type auction allow bidders to submit bids of equal value, and in an event of a tie, the seller randomizes equally among the bidders with the highest bid, then collusion, if mutually beneficial for all bidders, can be sustained as a Nash equilibrium of a one-shot auction game even without communication. All bidders submit exactly the same bid equal to the seller's reservation price, and the objects are assigned randomly; deviations are deterred by trigger or bid matching strategies within the same 
auction period. ${ }^{1}$ Our earlier results indicate that in a complete information environment with a small number of bidders where all bidders have common valuations for the objects, such collusion does occur in the oral auctions where bid matching is allowed (Sherstyuk, 1999). ${ }^{2}$

The occurrence of collusion in a complete information environment with symmetric bidders may not be surprising given a large body of experimental evidence which indicates that, generally, symmetry and complete information helps to sustain collusion (Holt, 1995). In this study, we relax the symmetric valuations, complete information assumption, and investigate the robustness of bidders' collusive behavior in private values, private information environments. When all bidders have identical valuations, competitive bidding invariably leads to zero profits to all bidders; the bidders have nothing to lose by colluding. However, if objects' valuations vary across bidders and are their private information, collusion may be harder to achieve and sustain. McAfee and McMillan (1992, p. 580 ) note that in order to collude, the bidders must resolve their asymmetric information problem: they must have some way of selecting a winner. In a recent study of bidder collusion in multi-unit sealed bid auctions with communication, Kwasnica (1998) reports that the subjects did not use simple random assignment rules to allocate the objects, but adopted collusive mechanisms that were more likely to assign the objects to the bidders with higher values. This indicates that efficiency considerations are important to subjects in deciding on object allocations. In oral auctions where no communication is allowed, it may be difficult for high value bidders to communicate their values to others without triggering competition. Further, the bidders' expected payoffs in competitive equilibrium are no longer zero; the opportunity cost of following competitive strategies is reduced as compared to the symmetric valuations case.

\footnotetext{
${ }^{1}$ McAfee and McMillan (1992) prove that, in a single-unit sealed bid auction where transfer payments among bidders are not possible, the optimal collusion involves all bidders submitting the same (minimal) bid for the object. The important difference is that in the oral auctions that allow for bid matching, such collusion can be sustained as a Nash equilibrium within one auction period; in the sealed bids, repeated play is necessary to sustain collusive outcomes.

${ }^{2}$ There is empirical evidence that auction rules that allow for bid matching lead to supracompetitive pricing even if the ties in bids of equal value are not broken randomly. In Cook County (Chicago), Illinois, contracts for tax lien collection are allocated in a sealed bid auction, where the ties are broken in favor of firms who have large historical market shares. Firms in this market now face a class-action antitrust lawsuit, alleging anticompetitive bidding. Another example is retail online auctions "Onsale" (http://www.onsale.com) that use the "Yankee auction" format. In a Yankee auction, one or more identical items are offered for sale at the same time. When the auction closes, the highest bidders win the available merchandise at their bid price. Bids are ranked in order of price, then quantity, then time of initial bid. During the auction, the information about the current highest bidders and their bids is posted at the web site. Bidders can also post a comment together with their bid. Bid matching is very common in these auctions, and comments such as "Keep it cheap" are not unusual.
} 
Below we report on the series of experiments that allow us to assess how bidders' collusive behavior is affected by the presence of private information on bidders' valuations. Further, we investigate whether collusion is sensitive to the degree of asymmetry in bidder valuations, payoff gains from collusion as compared to the competitive equilibrium, and subject pool training in other experimental markets.

\section{Experimental design}

To make a clear comparison between the complete information, symmetric valuation case studied earlier, and the private information, private values case considered here, most of the features of the experimental design are exactly as in Sherstyuk (1999). There are three bidders in the market and two identical objects for sale. Each bidder demands exactly one unit in a given period. The institution is the weekly ascending oral auction: each subsequent bid submitted to the market has to be no lower than the highest outstanding bid. The soft closing rule is used to end periods: the period is closed when no new bids are incoming for 30 seconds. At the end of the period, the units are allocated to the two highest bidders, provided that the bids are no lower than the seller's reservation price. Ties in the bids of acceptances, if any, are broken by random choice of buyer. ${ }^{3}$

In the benchmark experiments conducted at Melbourne university (Sherstyuk, 1999), all bidders had the same value of 100 experimental francs for the object, which was common knowledge. The seller's reservation price was 5 francs and was announced at the beginning of each period. One experimental franc was equal to one Australian cent. We will refer to these experiments as the benchmark common values $(\mathrm{C})$ treatment. In the present study, we consider two private values, private information treatments that differ only in the support from which the bidders private values were drawn. In the low asymmetry (PL) treatment, the values were drawn from the uniform distribution with the support of $[90,100]$ experimental francs; in the high asymmetry $(\mathrm{PH})$ treatment, the support was changed to $[50,100]$ francs. Bidder valuations and bids submitted were constrained to be integers. The seller's reservation price was 10 francs in both cases. ${ }^{4}$

The distributions of values and the seller's reservation price were chosen so that expected payoff gains from collusion relative to the competitive equilibrium were substantial in all cases. However, in the low asymmetry $[90,100]$ treatment the gains from collusion

\footnotetext{
${ }^{3}$ Experimental instructions are available from the author upon request.

${ }^{4}$ The reserve price of 10 , instead of 5 experimental francs, was announced by mistake in the first experimental session, and was then replicated in each session. The difference between 5 and 10 experimental francs was negligible.
} 
were higher, and the expected payoffs in the competitive equilibrium were lower, than in the high asymmetry [50,100] treatment. Theoretically, with 3 bidders and 2 objects, the competitive equilibrium price is equal to the lowest value drawn among the three bidders. If the values are drawn from the uniform distribution with the support $[\underline{v}, \bar{v}]$, then, in the competitive equilibrium, the expected payoff of bidder $i$ who has a value $v_{i}$ is:

$$
E P^{C E}\left(v_{i}\right)=\frac{\left(v_{i}-\underline{v}\right)^{2}}{(\bar{v}-\underline{v})^{2}}\left(\bar{v}-v_{i} / 3-2 \underline{v} / 3\right)
$$

If the bidders collude and all submit bids equal to the seller's reservation price $\underline{p}$, then under the auction rules considered, each bidder has a two thirds chance of buying the unit at the minimal price. ${ }^{5}$ The expected payoff from collusion, given a value of $v_{i}$, is:

$$
E P^{C o l l}\left(v_{i}\right)=2\left(v_{i}-\underline{p}\right) / 3
$$

Define the absolute expected gains from collusion as the difference between expected payoffs from the collusive and the competitive equilibrium outcomes:

$$
A G\left(v_{i}\right)=E P^{C o l l}\left(v_{i}\right)-E P^{C E}\left(v_{i}\right)
$$

Incentives to collude can be also measured by the relative expected gain from collusion which indicates the percentage gain from collusion relative to the competitive equilibrium payoff:

$$
R G\left(v_{i}\right)=\frac{E P^{C o l l}\left(v_{i}\right)-E P^{C E}\left(v_{i}\right)}{E P^{C E}\left(v_{i}\right)} \cdot 100 \%
$$

It is straightforward to show that as long as the seller's reservation price is no higher than the lower bound of the support of bidders' valuations, the relative gains from collusion are non-negative for all bidder types, but are strictly decreasing in bidder valuations. A bidder who draws the value of $\underline{v}$ is certain to gain nothing in the competitive outcome, and therefore has strong incentives to pursue collusion. On the contrary, a bidder who draws $\bar{v}$ expects a positive gain from the competitive outcome; his incentives to collude are therefore the minimal among all bidder types. Thus, we can compare the different treatments on the basis of gains from collusion to the bidder with the highest value. Table 1 presents such a comparison.

\footnotetext{
${ }^{5}$ As long as the seller's reservation price is low enough, there is a continuum of collusive levels of bids which give the bidders expected payoffs higher than in the competitive equilibrium. We focus our attention on the outcome that is payoff-dominant for the bidders in this class of outcomes, in the sense that it maximizes the bidders' joint payoff.
} 


\begin{tabular}{|c|c|c|c|c|}
\hline & $E P^{C E}(100)$ & $E P^{\text {Coll }}(100)$ & $A G(100)$ & $R G(100)$ \\
\hline Common values $(\mathrm{C}), v_{i}=100$ & 0.00 & 60.00 & 60.00 & $\infty$ \\
\hline $\begin{array}{l}\text { Private values, low asymmetry (PL) } \\
v_{i} \in[90,100] \\
\text { Private values, high asymmetry }(\mathrm{PH})\end{array}$ & 6.66 & 60.00 & 53.34 & $800.9 \%$ \\
\hline$v_{i} \in[50,100]$ & 33.33 & 60.00 & 26.67 & $79.98 \%$ \\
\hline
\end{tabular}

Table 1: Absolute and relative gains from collusion for the highest type bidder with $v_{i}=100$, given the reserve price $\underline{p}=10$. Payoffs and absolute gains are in experimental francs; relative gains are in percent.

The present design allows us to answer two questions of interest. First, can a small degree of asymmetry in bidder valuations break down the collusion that was observed under the common values, common information treatment? Second, how does collusive stability depend on bidders' incentives to collude, measured by the absolute and relative gains from collusion?

There are two additional questions that we seek to answer in this study. One is whether the absolute, or the relative payoff gains from collusion are more important for collusion occurrence and sustainability. Observe that both absolute and relative gains are higher under the PL than under the PH treatment, provided that a common exchange rate is used to convert experimental francs into dollars. Thus, we might expect the PL treatment to result in more collusive outcomes due to the absolute and/or relative gains increase. However, by varying the exchange rates for dollars across treatments, we can create the high and low asymmetry treatments that have identical absolute gains from collusion in dollar terms and differ only in relative gains, and thus investigate the effect of relative gains alone.

The other question is how bidder collusion in our experiments depends on subjects' previous training in other experimental markets. To answer these questions, we used two subject pools in our experiments: Melbourne university students (Australia) and Caltech students (USA). Most Melbourne university students had no prior experiences with experimental markets. Most Caltech students have previously participated in a number market experiments. The low and high asymmetry treatments with a common dollar exchange rates were tested on Melbourne university subjects. The design that isolated the effect of relative gains from collusion, keeping the absolute gains constant, was implemented on Caltech subject pool.

The features of experimental design are summarized in table $2 .{ }^{6}$

\footnotetext{
${ }^{6}$ Table 2 shows that the dollar exchange rates in Caltech experiments were higher than in Melbourne
} 


\begin{tabular}{lcccc}
\hline Treatment & \# of session & Exchange rate & $A G(100)$ & $R G(100)$ \\
\hline Melbourne, low asymmetry & 4 & 1 & 53.34 & $800.9 \%$ \\
Melbourne, high asymmetry & 4 & 1 & 26.66 & $79.98 \%$ \\
Caltech, low asymmetry & 4 & 1.5 & 80.01 & $800.9 \%$ \\
Caltech, high asymmetry & 4 & 3 & 80.01 & $79.98 \%$ \\
\hline
\end{tabular}

Table 2: Features of experimental design. Exchange rates show the worth of one experimental franc in cents (Australian and US cents, respectively). The absolute gains are in cents; the relative gains are in percent.

Procedures The total of sixteen experimental sessions were conducted: eight sessions at Melbourne university and eight sessions at Caltech. For each subject pool, four sessions were conducted under the low asymmetry (PL) treatment, $v_{i} \in[90,100]$, and four sessions under the high asymmetry $(\mathrm{PH})$ treatment, $v_{i} \in[50,100]$. The exchange rates used to convert experimental francs into respective countries' currencies are given in table 2 . All experimental procedures, other than the private value draws, were identical to the benchmark common values experiments conducted earlier at Melbourne (Sherstyuk, 1999). Most Melbourne university subjects were first or second year undergraduate students in economics and commerce, all recruited through posted flyers or class announcements. All Caltech subjects were recruited through a web recruitment program; there were both undergraduate and graduate students among the subjects. Each session was conducted with three subjects. All sessions were conducted as non-computerized experiments; the subjects were seated in a classroom, behind each other, and two rows away from each other, to guarantee that they could not see each other's faces. No communication was allowed. Each session consisted of 15 identical periods, preceded by one practice period. ${ }^{7}$ Bidders' private values were drawn for each subject at the beginning of each period by the experimenter. All bids together with bidder ID numbers were recorded on the overhead. Ties in the bids of acceptance were resolved in front of the subjects by an assistant or by one of the subjects, using cards marked with bidders' ID numbers. At the end of each experiment, subjects were paid their earnings in private, plus $\$ 5$ participation fee (Australian and US dollars, respectively).

experiments for both PL and PH treatments. Thus, one could argue that incentives to collude were slightly higher at Caltech than at Melbourne under both treatments. This argument is complicated by possible differences in subjects' opportunity costs and in purchasing power of Australian and US dollar in respective domestic markets. As will be discussed in the next section, the differences in the exchange rates between Melbourne and Caltech experiments do not prevent us from answering the research questions of interest.

${ }^{7}$ By a subject's request, one of Caltech sessions (PH-2) included two practice periods. 


\section{Results}

We first compare the overall performance of auctions under the various treatments, and then consider the role of bid matching is sustaining collusive outcomes.

\subsection{Overall performance}

The data from the four private values treatments are compared with the data from the benchmark common values experiments reported in Sherstyuk (1999). The results pooled by treatment and subject pool are summarized in figure 1 and table 3 . Since the competitive equilibrium price in a given period depends on specific realizations of bidders' values, we cannot use the observed auction prices to compare the auction outcomes within a treatment and across treatments. We use the following measure of auction competitiveness. Let $v^{1}, v^{2}$ and $v^{3}$ denote bidder valuations in a given period, ranked from the highest to the lowest. Let $b^{1}, b^{2}$ and $b^{3}$ denote the bidders' final bids, also ranked from the highest to the lowest. According to the competitive equilibrium prediction, $b^{1}=b^{2}=v^{3}$; according to the collusive equilibrium prediction, $b^{1}=b^{2}=\underline{p}$. The percentage of market competitiveness is given by:

$$
C o m p=\frac{b^{1}+b^{2}-2 \underline{p}}{2\left(v^{3}-\underline{p}\right)} \cdot 100 \%
$$

The market competitiveness is at $0 \%$ in the collusive equilibrium, and is at $100 \%$ in the competitive equilibrium. It will exceed $100 \%$ if the units are traded at prices above the competitive equilibrium prediction $v^{3} .^{8}$

\section{FIGURE 1 AROUND HERE}

The dynamics of average market competitiveness pooled by treatment is illustrated in figure 1. Figures 2-6 in the appendix graph the dynamics of market competitiveness in the common value auctions (benchmark) and the four treatments of the private value auctions, by session. The figures also report, for each session, the average market competitiveness and percentage of collusive-type matches in the end-of period bids (to be discussed in detail in section 3.2 below). Descriptive statistics on market competitiveness by treatment are summarized in table 3 . To trace possible effects of subjects' experience, we divided all

\footnotetext{
${ }^{8}$ This measure is closely related to the index of monopoly efectiveness used to evaluate the performance of market insitutions (e.g., Davis and Holt, 1993, p. 134). We use the market competitiveness measure since under our design, it closely traces, both graphically and numerically, the dynamics of auction trading prices.
} 


\begin{tabular}{|c|c|c|c|c|c|}
\hline $\begin{array}{l}\text { Mean } \\
(\text { Stddv })\end{array}$ & $\begin{array}{l}\text { Comp. } \\
\text { Eq }\end{array}$ & $\begin{array}{l}\text { Collu- } \\
\text { sive }\end{array}$ & Total & $\begin{array}{l}\text { Early } \\
\text { periods }\end{array}$ & $\begin{array}{c}\text { Late } \\
\text { periods }\end{array}$ \\
\hline Common values (C), Melbourne & 100 & 0 & $\begin{array}{l}21.03 \\
(34.31)\end{array}$ & $\begin{array}{c}23.17 \\
(31.62)\end{array}$ & $\begin{array}{l}18.72 \\
(37.40)\end{array}$ \\
\hline $\begin{array}{c}\text { Private values, low asymmetry (PL) } \\
\text { - Melbourne }\end{array}$ & 100 & 0 & $\begin{array}{c}56.27 \\
(45.64)\end{array}$ & $\begin{array}{l}77.05 \\
(35.81)\end{array}$ & $\begin{array}{c}35.48 \\
(45.38)\end{array}$ \\
\hline $\begin{array}{c}\text { Private values, low asymmetry (PL) } \\
- \text { Caltech }\end{array}$ & 100 & 0 & $\begin{array}{c}30.52 \\
(42.42)\end{array}$ & $\begin{array}{c}36.31 \\
(41.09)\end{array}$ & $\begin{array}{c}24.89 \\
(43.55)\end{array}$ \\
\hline $\begin{array}{c}\text { Private values, high asymmetry }(\mathrm{PH}) \\
- \text { Melbourne }\end{array}$ & 100 & 0 & $\begin{array}{l}103.43 \\
(6.95)\end{array}$ & $\begin{array}{l}103.00 \\
(6.98)\end{array}$ & $\begin{array}{l}103.9 \\
(7.00)\end{array}$ \\
\hline $\begin{array}{c}\text { Private values, high asymmetry }(\mathrm{PH}) \\
- \text { Caltech }\end{array}$ & 100 & 0 & $\begin{array}{c}45.23 \\
(47.16)\end{array}$ & $\begin{array}{c}66.23 \\
(43.64)\end{array}$ & $\begin{array}{c}24.23 \\
(41.29)\end{array}$ \\
\hline
\end{tabular}

Table 3: Market competitiveness in the weakly ascending oral auctions under common and private value treatments, pooled data, percent.

observations into two time intervals: the early periods (periods 1-8), and the late periods (periods 9-16). ${ }^{9}$ Consideration of the data leads to the following results.

Result 1 Private values and asymmetry alone were not sufficient to break down the collusion in the oral auctions where the gains from collusion were high. Collusive tendencies were present and persisted under the private values, low asymmetry treatment in Melbourne experiments, and under both private value treatments in Caltech experiments.

Support: Figures 1, 3, 5-6, table 3. The average across experiments value of market competitiveness under the private values, low asymmetry (PL) treatment was $56.27 \%$ (Melbourne), $30.52 \%$ (Caltech); it was $45.23 \%$ under the private value, high asymmetry ( $\mathrm{PH})$ treatment for Caltech. These values were below the competitive equilibrium prediction of $100 \%$ at the $5 \%$ level of significance according to the $t$-test (one-tailed). ${ }^{10}$ Moreover, the competitiveness decreased from the early periods to the late periods in all three of these treatments.

Result 2 The incidence and stability of bidder collusion was sensitive to payoff gains from collusion. Collusive tendencies became less pronounced and broke down as payoff gains from collusion decreased in Melbourne experiments. Collusion was sustained in Caltech experiments where absolute payoff gains from collusion remained high.

\footnotetext{
${ }^{9}$ Period 1 was the practice period. We include it in the data analysis since it may contain valuable information about the subjects' initial perceptions of the game.

${ }^{10}$ In the $t$-tests, mean per experiment values were taken as units of observation.
} 
Support: Figures 1-6, table 3. For Melbourne experiments, where the C, PL and PH treatment were clearly ranked by both absolute and relative gains from collusion, the mean market competitiveness increased from $21.03 \%$ under the $\mathrm{C}$ treatment, to $56.27 \%$ under the PL treatment, to $103.43 \%$ under the PH treatment. According to the permutation test (Siegel and Castellan, 1988, pp. 151-155), the average per experiment competitiveness was higher in the PL treatment than in the $\mathrm{C}$ treatment at the significance level of $2.9 \%$ (onetailed). The average per experiment competitiveness was higher in the $\mathrm{PH}$ treatment than in the PL treatment at the significance level of $1.4 \%$ (one-tailed). In the $\mathrm{PH}$ treatment, the market competitiveness exceeded the competitive equilibrium prediction of $100 \%$. For Caltech experiments, where the absolute gains from collusion were the same under the PL and $\mathrm{PH}$ treatments, the hypothesis of no difference in market competitiveness between these treatments is sustained with the $p$-value of $30.0 \%$ (one-tailed).

Result 3 Previous training in market experiments and higher monetary incentives increased bidder collusion: Overall, bidder collusion was higher in Caltech experiments than in Melbourne experiments.

Support: Figure 1, table 3. The permutation test shows that the average per experiment market competitiveness under the PL treatment was lower for Caltech than for Melbourne with the $p$-value of $7.1 \%$ (one-tailed). The average market competitiveness under the $\mathrm{PH}$ treatment was lower for Caltech than for Melbourne with the $p$-value of $1.4 \%$ (one-tailed).

Result 4 In Caltech experiments, the absolute gains from collusion were decisive for collusion occurrence and sustainability: the amount of bidder collusion was not significantly different between the PL and PH treatments.

Support: See support for result 2. Remarkably, in three out of four sessions under the $\mathrm{PH}$ treatment at Caltech, the payoff-dominant collusive outcome was sustained in the late periods: the market competitiveness was close to $0 \%$ (table 3 , figure 6 ).

To summarize, we find that under an auction institution which allows for implicit coordination of bidder strategies, the incidence of bidder collusion strongly depends on bidders' incentives to collude, measure by payoff gains from collusion. Interesting differences in behavior are observed between an inexperienced and a well-trained subject pools (Melbourne and Caltech subjects, respectively). The dynamics of Melbourne experiments suggests that, as a rule, collusion emerged only after the subjects experienced low payoffs 
at the competitive equilibrium: consider the market dynamics in the early periods under the $\mathrm{C}$ and the $\mathrm{PL}$ treatments (figures 2 and 3). Under the $\mathrm{PH}$ treatment, where the competitive equilibrium payoffs were non-negligible, collusive tendencies never emerged (figure 4). This evidence suggests that for inexperienced subject pools, collusion is driven by relative, rather than absolute, payoff gains. However, Caltech experiments demonstrate that more experienced subjects pursue the absolute payoff gains. As it is evident from the $\mathrm{PH}$ treatment at Caltech, private values, high value asymmetry and non-negligible competitive equilibrium payoffs were not sufficient for the auctions to result in competitive outcomes.

\subsection{The role of bid matching}

We now turn to the role of the absence of the strict bid improvement rule in sustaining collusive outcomes. How often was bid matching used to achieve and maintain collusion? To answer this question, we classify all auction outcomes into three types. We will call an outcome collusive if the highest closing bid in the market is below the lower bound of the private values support: $b^{1}<\underline{v}$. As discussed in section 2 , in such an outcome a bidder with any value (including the highest value of 100 francs) is at least as well off as in the competitive equilibrium, provided that he has a two thirds chance of winning the unit. We will call all other outcomes competitive. Further observe that collusive outcomes may be of only two types: (i) Collusive bid matching outcomes, where all three bidders have a positive chance of winning a unit within the same period (these involve three-way symmetric matches in the highest bids, $b^{1}=b^{2}=b^{3}$, or two-way asymmetric matches in the lower bids, $b^{1}>b^{2}=b^{3}$ ); or (ii) Bid rotation outcomes, where one of the bidders stays (or prematurely drops) out of the competitive bidding process (hence, $b^{1} \geq b^{2}>b^{3}$ ). While collusive bid matching outcomes can be sustained as Nash equilibria within one auction period, repeated play is necessary to sustain bid rotation outcomes.

Table 4 displays the percentages of auction outcomes by type, pooled by treatment. ${ }^{11}$ The percentages of collusive type matches in the end-of-period bids (irrespective of auction outcomes) for individual sessions are reported in figures 2-6. We conclude the following.

\footnotetext{
${ }^{11}$ In the results reported in table 4, we classified outcomes as collusive if $b^{1} \leq(\underline{v}-5)$ (not if $b^{1}<\underline{v}$ ); all other outcomes were considered competitive. Under such a classification, colluisve outcomes guaranteed minimal positive gains for bidders of any type, and were therefore qualitatively different from competitive outcomes.
} 


\begin{tabular}{lccccc}
\hline \% & $\begin{array}{c}\# \\
\text { of obs. }\end{array}$ & $\begin{array}{c}\text { Competitive } \\
\text { outcome }\end{array}$ & $\begin{array}{c}\text { Collusive } \\
\text { bid match }\end{array}$ & $\begin{array}{c}\text { Collusive } \\
\text { bid rotation }\end{array}$ & All \\
\hline PL - Melbourne, all & 64 & 53.1 & 34.4 & 12.5 & 100 \\
-early periods & 32 & 71.9 & 15.6 & 12.5 & 100 \\
-late periods & 32 & 34.4 & 53.1 & 12.5 & 100 \\
& & & & & \\
PL - Caltech, all & 64 & 28.1 & 40.6 & 31.2 & 100 \\
-early periods & 32 & 31.2 & 31.2 & 37.5 & 100 \\
-late periods & 32 & 25.0 & 50.0 & 25.0 & 100 \\
& & & & & \\
PH - Melbourne, all & 64 & 100.0 & - & - & 100 \\
-early periods & 32 & 100.0 & - & - & 100 \\
-late periods & 32 & 100.0 & - & - & 100 \\
& & & & & \\
PH - Caltech, all & 65 & 46.2 & 24.6 & 29.2 & 100 \\
-early periods & 32 & 68.8 & 18.8 & 12.5 & 100 \\
-late periods & 33 & 24.2 & 30.3 & 45.5 & 100 \\
\hline
\end{tabular}

Table 4: Frequencies of auction outcomes by type, $\%$

Result 5 Bid matching was the most frequently used method to achieve and sustain collusion in Melbourne and Caltech low asymmetry experiments. Both bid rotation and bid matching were used to sustain collusion in Caltech high asymmetry experiments.

Support: Table 4, figures 2-6. $34.4 \%$ of all PL outcomes in Melbourne and $40.6 \%$ of all PL outcomes at Caltech were collusive outcomes which involved bid matches. In the late periods, these percentages increased to $53.1 \%$ and $50.0 \%$, respectively. In Caltech $\mathrm{PH}$ experiments, $29.2 \%$ of outcomes were collusive bid rotation outcomes, as compared to $24.6 \%$ collusive bid matching outcomes; in the late periods, the percentage of bid rotation outcomes increased to $45.5 \%$. For individual sessions, collusive bid matching was most frequently used in three PL sessions in Melbourne (PL-1: $68.7 \%$ collusive outcomes, PL3: $25 \%$ outcomes, PL-4: $43.8 \%$ outcomes), and three PL sessions and one PH session at Caltech (PL-1: 37.5\% outcomes, PL-2: 50\% outcomes, PL-4: 56.2\% outcomes, PH-1: 75\% outcomes). Collusive bid rotation was widely used in two PH sessions and one PL session at Caltech (PH-2: 52.9\% outcomes, PH-3: 62.5\% outcomes; PL-3: 81.2\% outcomes), and in only one PL session in Melbourne (PL-2: 37.5\%). The majority (over $80 \%$ for both Melbourne and Caltech) of competitive outcomes did note involve bid matches of collusive types.

Arguably, in an auction where explicit communication is not allowed, bid matching is 
easier for bidders to adopt than bid rotation: under bid matching, the objects are allocated randomly, whereas under bid rotation, the bidders have to find a way to coordinate whose turn it is to win the objects. It is then not surprising that inexperienced Melbourne subjects overwhelmingly adopted bid matching schemes; what is fascinating is the ability of Caltech subjects to adopt bid rotation schemes in some cases. ${ }^{12}$ From the bidders' perspective, bid rotation may have various advantages over bid matching. Bid rotation eliminates uncertainty; if bidders take turns in staying out, then each bidder is guaranteed to get the object in two thirds of the auctions in a session. Further, if bidders pursue efficiency and are somehow able to communicate a likely ranking of their private valuations, then bid rotation can achieve higher market efficiency than bid matching. The market efficiency is defined as the percentage of the maximal social surplus realized in the market:

$$
E f f=\frac{\sum_{i=1}^{3} v_{i} x_{i}-2 \underline{p}}{v^{1}+v^{2}-2 \underline{p}} \cdot 100 \%,
$$

where $v_{i}$ and $x_{i}$ denote the object valuation and the assignment coefficient of bidder $i$ ( $x_{i}=1$ if bidder $i$ wins the object, and $x_{i}=0$ otherwise), and $v^{j}$ denotes the $j$-th highest value drawn among the bidders. Under the competitive equilibrium prediction, the market efficiency is 100\%; under collusion, efficiency losses occur unless the bidders find a way to allocate the objects to the bidders with the two highest values.

Consider whether, in fact, collusion resulted in efficiency losses in our experiments, and whether bid rotation outcomes were any different from bid matching outcomes in terms of their efficiency. Table 5 displays the theoretically predicted and experimentally observed market efficiencies by treatment and by type of outcome. ${ }^{13}$ Interestingly, we find that efficiency losses under collusion were minimal and below the theoretical predictions.

Result 6 Overall, there were no efficiency losses due to collusion in either Melbourne or Caltech experiments. The average market efficiency under collusive outcomes was no different than under competitive outcomes. The efficiency of collusive outcomes under the PH treatment at Caltech was higher than theoretically predicted. The differences in efficiencies between the bid matching and bid rotation outcomes were minimal.

\footnotetext{
${ }^{12}$ Coordination problems may be easier to overcome if subjects in the same session knew each other. We did not allow any sessions in which all three subjects were aquainted with each other. In both Melbourne and Caltech experiments, there were some sessions where two subjects knew each other; the number of such sessions was about the same at Melbourne and Caltech.

${ }^{13}$ The theoretical predictions for bid rotation outcomes given in table 5 were obtained assuming that the objects are allocated to bidders in turn and independently of their private valuations. The predicted efficiencies are therefore identical for the bid rotation and bid matching collusive outcomes. The estimates of the efficiencies of collusive outcomes were obtained through computer simulations.
} 


\begin{tabular}{|c|c|c|c|c|}
\hline $\begin{array}{l}\text { Mean, \% } \\
\text { (Stddv) }\end{array}$ & $\begin{array}{c}\text { Competitive } \\
\text { outcome }\end{array}$ & $\begin{array}{l}\text { Collusive } \\
\text { bid match }\end{array}$ & $\begin{array}{c}\text { Collusive } \\
\text { bid rotation }\end{array}$ & All \\
\hline PL - predicted & $\begin{array}{c}100 \\
(0)\end{array}$ & $\begin{array}{c}98.56 \\
(1.53)\end{array}$ & $\begin{array}{c}98.56 \\
(1.53)\end{array}$ & - \\
\hline - Melbourne data & $\begin{array}{l}97.93 \\
(9.46)\end{array}$ & $\begin{array}{l}98.38 \\
(1.56)\end{array}$ & $\begin{array}{l}97.98 \\
(1.92)\end{array}$ & $\begin{array}{l}98.10 \\
(6.94)\end{array}$ \\
\hline - Caltech data & $\begin{array}{l}96.53 \\
(0.13)\end{array}$ & $\begin{array}{l}98.21 \\
(1.90)\end{array}$ & $\begin{array}{l}97.96 \\
(2.03)\end{array}$ & $\begin{array}{l}97.66 \\
(7.08)\end{array}$ \\
\hline $\mathrm{PH}$ - predicted & $\begin{array}{l}100 \\
(0)\end{array}$ & $\begin{array}{l}91.32 \\
(9.00)\end{array}$ & $\begin{array}{l}91.32 \\
(9.00)\end{array}$ & - \\
\hline - Melbourne data & $\begin{array}{l}99.63 \\
(1.47)\end{array}$ & - & - & $\begin{array}{l}99.63 \\
(1.47)\end{array}$ \\
\hline - Caltech data & $\begin{array}{l}96.94 \\
(0.10)\end{array}$ & $\begin{array}{l}94.57 \\
(9.08)\end{array}$ & $\begin{array}{l}96.57 \\
(6.15)\end{array}$ & $\begin{array}{l}96.25 \\
(8.98)\end{array}$ \\
\hline
\end{tabular}

Table 5: Market efficiencies of auction outcomes by type, $\%$

Support: Table 5. In the PL treatments at both Melbourne and Caltech, the average market efficiencies under competitive outcomes were no higher than under either collusive bid matching or bid rotation outcomes. In the $\mathrm{PH}$ experiments at Caltech, the average market efficiencies under collusive and bid matching outcomes were $94.57 \%$ and $96.57 \%$, respectively, as compared to $96.94 \%$ for competitive outcomes, and the theoretical prediction of $91.32 \%$ for collusive outcomes.

\section{Discussion}

The above results provide interesting insight into the nature and stability of bidder collusion in oral auctions with a small number of bidders. We conclude that it is not the complete information and symmetry as such that is necessary for the emergence and sustainability of collusion. Rather, it is the bidders' common knowledge of potentially high gains from collusion. Under the private values treatments where the gains from collusion were high, collusive tendencies did emerge and increase with bidders' experience; it is evident from figures 2, 3,5 and 6 that the dynamics of the private values, high payoff gains experiments (PL experiments at Melbourne and both PL and PH experiments at Caltech) were quite similar to the common values experiments. On the other hand, we observe that decreasing gains from collusion contribute to the breakdown of collusive tendencies. In the PH experiments at Melbourne, where the expected payoffs from collusion were twice as low as under the PL treatment, we observed no incidence of collusion. 
We have obtained a strong experimental evidence that the absence of the strict improvement rule in ascending price oral auctions can be very favorable for bidder collusion and equally detrimental for auctioneer's revenue. Bid matching was the most widely used collusive method that was easily adopted by both inexperienced and well-trained subjects. Interestingly, however, we found that bidder collusion did not affect the market efficiency in our experiments to the extent predicted by the theory.

We found that the subjects' ability to achieve and sustain collusion increased with their previous training in other experimental markets. Caltech experiments resulted in higher bidder collusion than Melbourne experiments, and Caltech subjects were able to adopt a broader variety of collusive schemes than Melbourne subjects. This suggests that although the absence of the bid improvement rule significantly facilitates bidder collusion, one could expect well-trained bidders to engage in tacit collusion even under less "favorable" institutional arrangements (see also footnote 2 in section 1 ). Investigation of other institutional features that help to safeguard against bidder collusion in ascending auctions with a small number of bidders would constitute an interesting topic for further research.

\section{Appendix}

\section{FIGURES 2-6 HERE}

\section{References}

[1] Artale, A. (1997). Rings in Auctions: An Experimental Approach. Springer-Verlag.

[2] Clauser, L., and Plott, C.R. (1993). "On the anatomy of the 'nonfacilitating' features of the double auction institution in conspiratorial markets." In D. Friedman, and J. Rust (eds.), The Double Auction Market (SFI Studies in the Sciences of Complexity, Proc. V. 14). Addison-Wesley. Chapter 12.

[3] Crampton, P. (1998). "Ascending auctions," European Economic Review: 42, 745756.

[4] Davis, D., and Holt, C. (1993). Experimental Economics. Princeton University Press.

[5] Graham, D.A., and Marshall, R.C. (1987). "Collusive bidder behavior at single-object second price and English auctions." Journal of Political Economy. 95, 1217-1239. 
[6] Holt, C.A. (1995). "Industrial organization: a Survey of laboratory research." In J. Kagel, and R. Roth (eds.), Handbook of Experimental Economics. Princeton University Press, 349-443.

[7] Isaac, M.R., and Plott, C.R. (1981). "The opportunity for conspiracy in restraint of trade." Journal of Economic Behavior and Organization. 2, 1-30.

[8] Isaac, M.R., Ramey, V., and Williams A.W. (1984). "The effects of market organization on conspiracies in restraint of trade." Journal of Economic Behavior and Organization. 5, 191-222.

[9] Isaac, M.R., and Walker, J. (1985). "Information and conspiracy in sealed bid auctions." Journal of Economic Behavior and Organization. 6, 139-159.

[10] Kwasnica, A.M. (1998). "Collusion in multiple object simultaneous auctions: theory and experiments." Caltech Social Science working paper 1010.

[11] McAfee, R.P., and McMillan, J. (1992). "Bidding rings." American Economic Review. $92(3), 579-599$.

[12] McAfee, R.P., and McMillan, J. (1996). "Analyzing the airwaves auctions." Journal of Economic Perspectives. 10, 159-175.

[13] Milgrom, P. (1987). "Auction theory." In T.Bewley (ed.), Advances of Economic Theory, Fifth World Congress. Cambridge University Press.

[14] Milgrom, P. (1998). "Game theory and spectrum auctions," European Economic Review. 42, 771-778.

[15] Saijo, T., Une, M., and Yamaguchi, T. (1996). “'Dango' experiments.” Journal of the Japanese and International Economies. 10, 1-11.

[16] Sherstyuk, K. (1999). "Collusion without conspiracy: an experimental study of onesided auctions." Experimental Economics, forthcoming.

[17] Siegel, S., and Castellan, N.J. Jr. (1988). Nonparametric Statistics for the Behavioral Sciences. McGraw-Hill Book Company. 


\section{List of figures}

Figure 1 The dynamics of mean per period market competitiveness, by treatment. Above: Melbourne experiments; below: Caltech experiments.

Figure 2 The dynamics of market competitiveness in the common values, complete information experiments, Melbourne. Comp: average market competitiveness; Match: percentage of collusive-type matches in the end-of period bids.

Figure 3 Figure 2. The dynamics of market competitiveness in the private values, low asymmetry experiments, Melbourne. Comp: average market competitiveness; Match: percentage of collusive-type matches in the end-of period bids.

Figure 4 The dynamics of market competitiveness in the private values, high asymmetry experiments, Melbourne. Comp: average market competitiveness; Match: percentage of collusive-type matches in the end-of period bids.

Figure 5 Figure 2. The dynamics of market competitiveness in the private values, low asymmetry experiments, Caltech. Comp: average market competitiveness; Match: percentage of collusive-type matches in the end-of period bids.

Figure 6 The dynamics of market competitiveness in the private values, high asymmetry experiments, Caltech. Comp: average market competitiveness; Match: percentage of collusive-type matches in the end-of period bids. 
PH-1 CIT: Comp=20.40\%, Match $=87.5 \%$

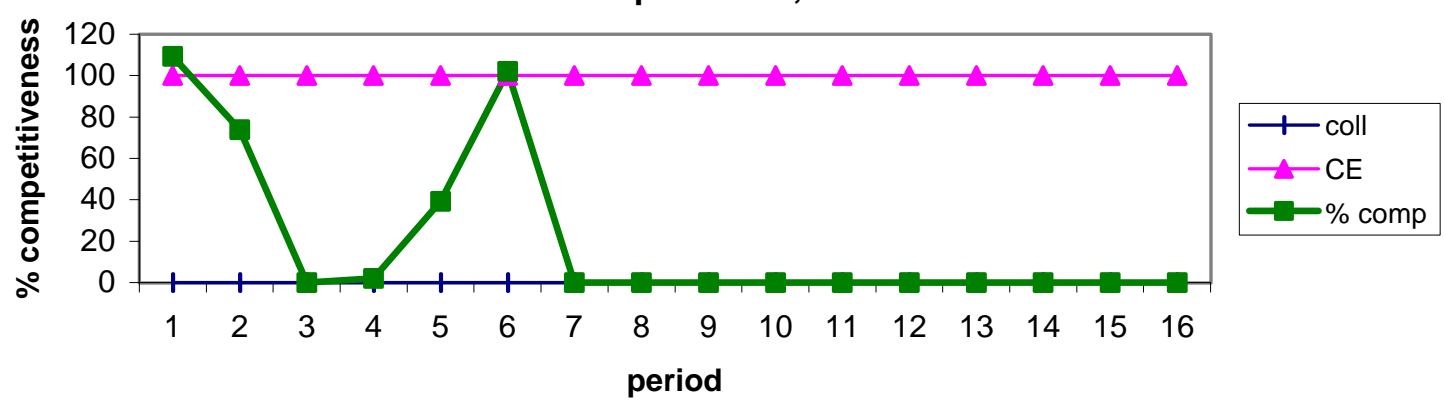

PH-2 CIT: Comp=42.50\%, Match $=5.9 \%$

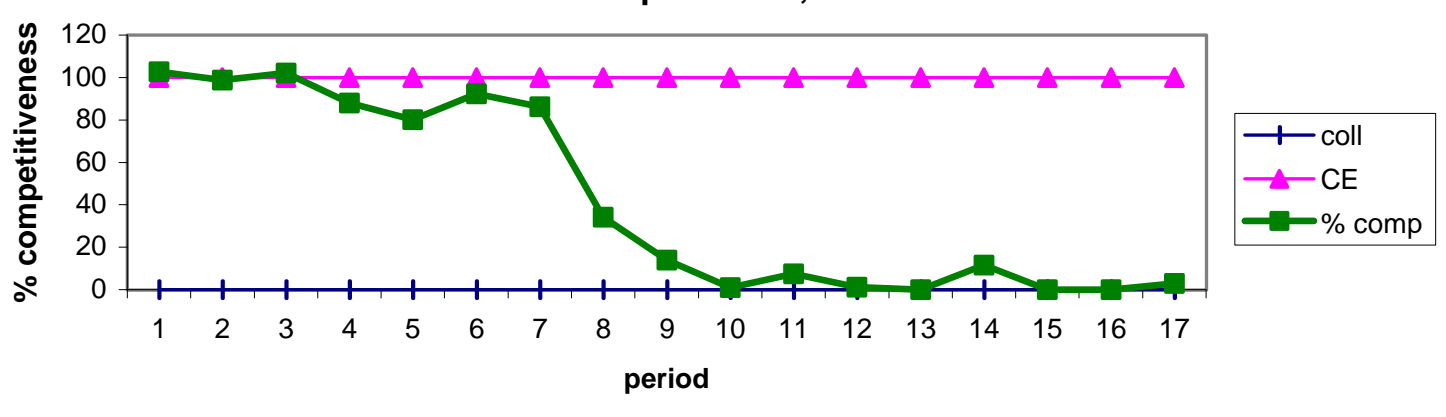

PH-3 CIT: Comp=19.37\%, Match $=18.8 \%$
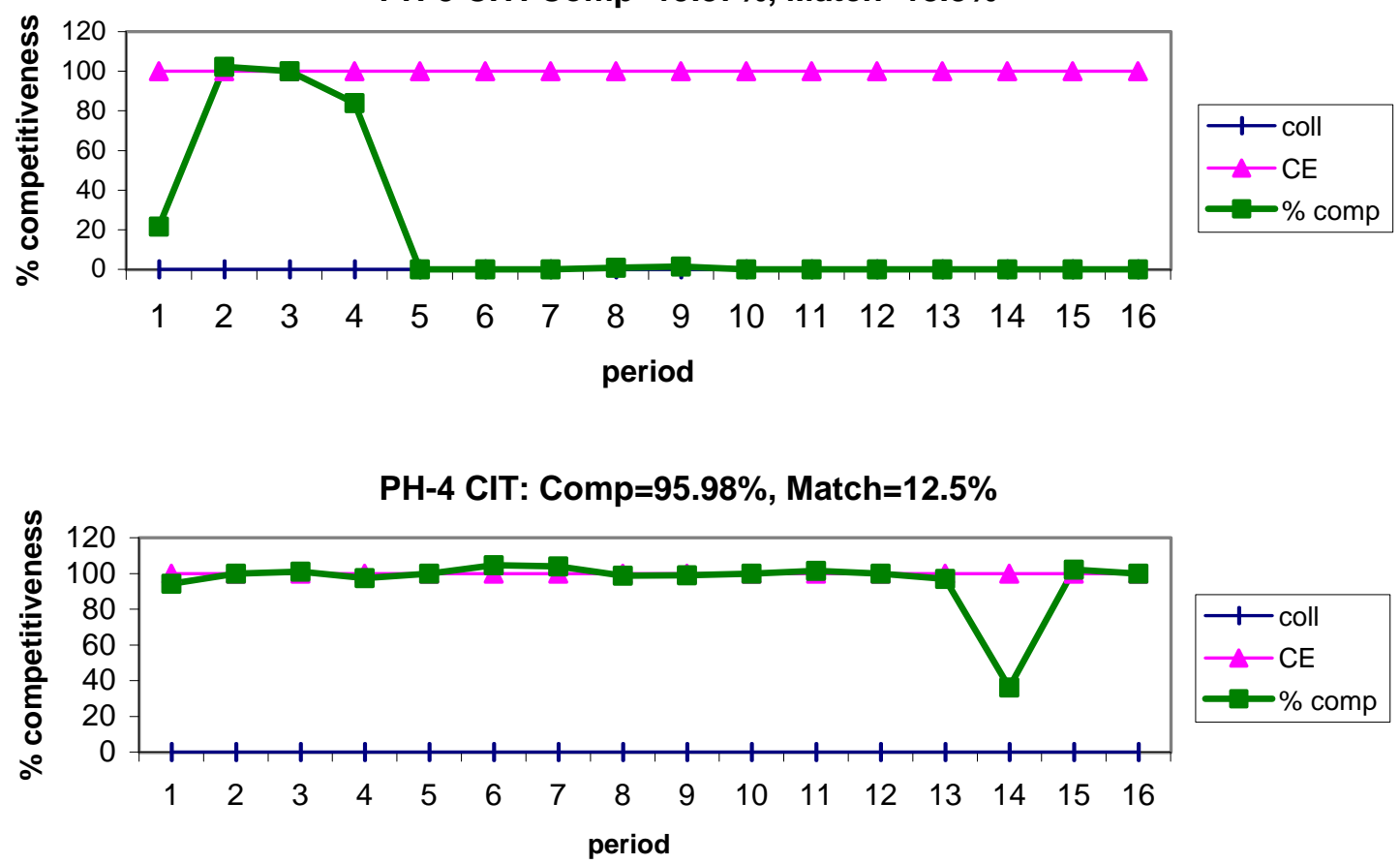

Figure 6: Private values, high asymmetry experiments, Caltech 